\title{
A RELAÇÃO ENTRE O NÍVEL VOLUNTÁRIO DE TRANSPARÊNCIA E O CUSTO DE CAPITAL PRÓPRIO DAS EMPRESAS BRASILEIRAS NÃO-FINANCEIRAS
}

\author{
Francisco Henrique Figueiredo de Castro Junior \\ henrique.castro@fecap.br \\ Fundação Escola de Comércio Álvares Penteado - São Paulo, SP/Brasil \\ Paula Meneghesso da Conceição \\ paulameneghesso@yahoo.com.br \\ Universidade Presbiteriana Mackenzie - São Paulo, SP/Brasil \\ Débora Antunes Santos \\ debora_antunessantos@yahoo.com.br \\ Universidade Presbiteriana Mackenzie - São Paulo, SP/Brasil
}

\begin{abstract}
Recebido em 11/11/2009
Aprovado em 02/03/2011

Disponibilizado em 01/12/2011

Avaliado pelo sistema double blind review

Revista Eletrônica de Administração

Editor: Luís Felipe Nascimento

ISSN 1413-2311 (versão on-line)

Editada pela Escola de Administração da Universidade Federal do Rio Grande do Sul.

Periodicidade: Quadrimestral
\end{abstract}

Sistema requerido: Adobe Acrobat Reader.

\section{RESUMO}

O objetivo principal desta pesquisa é verificar empiricamente a existência de relação significativa entre o nível de disclosure voluntário de informações e custo de capital próprio de empresas brasileiras não financeiras. É esperado que um maior nível de disclosure esteja relacionado a um menor custo de capital próprio pela redução do risco percebido pelos investidores. A fim de medir o nível de disclosure voluntário das empresas foi utilizado um questionário desenvolvido para este fim. O custo de capital próprio foi obtido com base em informações publicamente disponíveis das empresas. Foi encontrada uma relação negativa e significante entre as variáveis de interesse, indicando que as empresas que mais divulgam informações voluntariamente conseguem captar capital próprio a uma taxa mais barata.

Palavras-chave: Transparência, custo de capital próprio, governança corporativa. 
A relação entre o nível voluntário de transparência e o custo de capital próprio das empresas brasileiras não-financeiras

\title{
THE RELATIONSHIP BETWEEN THE LEVEL OF VOLUNTARY DISCLOSURE AND THE COST OF EQUITY CAPITAL IN NON-FINANCIAL BRAZILIAN COMPANIES
}

\begin{abstract}
The main objective of this research is to examine empirically the existence of a significant relationship between the level of voluntary disclosure of information and the cost of equity capital of Brazilian non-financial companies. It is expected that a greater level of disclosure is related to a lower cost of capital by reducing the risk perceived by investors. In order to measure the level of voluntary disclosure of the companies, a questionnaire developed for this purpose was used. The cost of equity capital was obtained from publicly available information. A negative and significant relationship between the variables of interest was found, indicating that companies that disclose more information voluntarily has a lower cost of equity capital.
\end{abstract}

Keywords: Disclosure, cost of equity capital, corporate governance.

\section{INTRODUÇÃO}

A Governança Corporativa é um conjunto de práticas, que, segundo a CVM (2002), tem por finalidade aperfeiçoar o desempenho de uma companhia protegendo suas partes interessadas, tais como investidores, empregados e credores, facilitando o acesso ao capital. Boas práticas de Governança proporcionam aos acionistas ou cotistas das empresas uma maior gestão estratégica e o efetivo controle da direção executiva.

A adesão às boas práticas de Governança Corporativa não é compulsória às empresas, sendo sua adoção, bem como a intensidade desta adoção, decorrente do seu objetivo de captar recursos próprios ou de terceiros a um menor custo. Entre os princípios apresentados pela Governança, o disclosure, ou transparência, é um fator importante para a adequada avaliação das oportunidades de investimentos no mercado financeiro. $\mathrm{O}$ disclosure busca prover maior $\mathrm{e}$ melhor informação aos acionistas e potenciais investidores, reduzir a assimetria informacional, e, consequentemente, reduzir o custo de capital próprio da empresa.

Conforme Botosan (1997) duas vertentes defendem uma relação negativa entre custo de capital e o nível de disclosure. A primeira delas inclui pesquisas de Glosten e Milgrom (1985), Amihud e Mendelson (1991), Diamond e Verrecchia (1991) e Bloomfield e Wilks (2000). Estes autores defendem que o maior nível de disclosure aumenta a liquidez das ações, reduzindo os custos de transação ou aumentando a demanda pelas ações da empresa e, em consequência, reduz-se o custo de capital. 
A segunda vertente defende que o maior nível de disclosure reduz o custo de capital pela redução do risco não diversificável. Essa linha de pesquisa é defendida por Barry e Brown (1985), Klein e Bawa (1976), Handa e Linn (1993) e Coles et al. (1995).

No Brasil, as pesquisas desenvolvidas por Alencar (2005), Gomes (2006) e Mazer (2007) buscam relacionar, de maneiras diferentes, o nível de disclosure das empresas e seu custo de capital. Outras pesquisas relacionam disclosure com outros fatores como o custo de capital de terceiros (LIMA et al., 2007), governança corporativa (LANZANA, 2004), valor das empresas (GARCIA; SATO; CASELANI, 2004) ou ainda com a volatilidade das ações (MALACRIDA; YAMAMOTO, 2006).

O objetivo principal desta pesquisa é testar empiricamente a hipótese de que há uma relação significativa entre o nível de disclosure voluntário de informações e o custo de capital próprio de empresas brasileiras não financeiras segundo a vertente que defende que o maior nível de disclosure reduz o custo de capital pela redução do risco não diversificável das empresas.

Para atingir esse objetivo, em primeiro lugar, é necessário entender o conceito de disclosure e relacioná-lo, à luz da teoria de finanças, a um consequente menor custo de capital nas empresas. Isto será feito na seção 2. Em seguida, será necessário dispor de um instrumento que possibilite mensurar o nível de disclosure das empresas. O detalhamento deste instrumento será feito na seção 3. Nesta seção também serão apresentados os demais procedimentos metodológicos que permitirão testar a hipótese desta pesquisa. Na seção 4 serão apresentados os resultados da pesquisa, e a conclusão será apresentada na seção 5.

\section{REFERENCIAL TEÓRICO}

Segundo o Instituto Brasileiro de Governança Corporativa (IBGC, 2009) a administração de uma empresa deve cultivar o desejo de informar, pois é com uma boa comunicação, interna e externa, que um clima de confiança com o mercado é alcançado. Conforme Bushman, Piotroski e Smith (2004), disclosure pode ser definido como a ampla disponibilização de informações a respeito de empresas listadas e que é de interesse para os agentes do mercado.

A importância do disclosure para o mercado de capitais ficou evidenciada com a Lei Sarbanes-Oxley, publicada em 2002. A nova legislação para o mercado americano buscou tratar importantes questões relacionadas a problemas de agência e à resolução do conflito de 
A relação entre o nível voluntário de transparência e o custo de capital próprio das empresas brasileiras não-financeiras

interesses entre gestores e acionistas, bem como responsabilizar legalmente os principais executivos das empresas em caso de falhas ou omissões em relatórios contábeis fundamentais para o acompanhamento dos resultados financeiros da empresa (GOMES, 2006).

Assim como o ocorrido nos Estados Unidos, órgãos reguladores em diversos países enrijeceram a legislação no mercado de capitais. No Brasil, para incentivar um maior nível de disclosure nas companhias brasileiras, a Bolsa de Valores de São Paulo (BOVESPA) lançou em dezembro de 2000 os níveis diferenciados de Governança Corporativa. Seguindo a mesma linha, a CVM publicou em 2002 algumas recomendações sob a forma de uma cartilha.

Segundo Lanzana (2004), em mercados emergentes a questão da abertura voluntária de informações é ainda mais crítica, pois a legislação é menos rígida, há alta concentração acionária e fortes particularidades causam maior insegurança aos investidores nesses países.

Bushman e Smith (2003) defendem que a divulgação de informação contábil é essencial para avaliação de oportunidades de investimento em uma economia, tanto para os gestores ao escolherem um projeto, quanto para os investidores alocarem seus recursos de forma eficiente. Outro fator importante do disclosure é que o mesmo contribui para a redução da assimetria informacional. Segundo Healy e Palepu (2000), o problema da assimetria informacional ocorre, porque os empreendedores detêm melhores informações sobre o negócio que os investidores.

Para Brown, Finn e Hillegeist (2001), o problema de assimetria informacional surge quando a companhia possui uma informação de valor que ainda não foi divulgada ao público, mas foi disponibilizada para alguns investidores de forma privada. Até que esta informação esteja disponível para o público, cria-se um problema de seleção adversa impondo assim risco informacional para os investidores não-informados. Como este investidor tende a se proteger do risco informacional, exigirá maiores retornos elevando dessa forma o custo de capital da empresa.

Neste contexto, conforme Verrecchia (2001), é desejável que a empresa reduza voluntariamente o problema de assimetria tornando a comunicação entre gestores, acionistas e o mercado em geral, mais aberta, a fim de reduzir seu custo de capital. No Brasil, os resultados encontrados em pesquisas anteriores não conseguiram, de maneira consistente, rejeitar a hipótese de que não há relação entre o nível de disclosure e o custo de capital das empresas. Alencar (2005) testou esta hipótese relacionando uma medida de disclosure baseada na quantidade de vezes que uma empresa foi indicada ao prêmio transparência da Associação Nacional dos Executivos de Finanças, Administração e Contabilidade 
(ANEFAC). Para medir custo de capital próprio, a autora usou, separadamente, ações ordinárias e preferenciais, não encontrando relação significativa em nenhuma das duas versões.

Gomes (2006) utilizou em sua pesquisa 3 diferentes índices de disclosure, sendo dois deles construídos na forma de variáveis dummy. A outra variável foi calculada com base na nota obtida pelas empresas no Prêmio da Associação Brasileira de Companhias Abertas (ABRASCA) de 2003, que avalia os melhores relatórios anuais com base em critérios que vão desde o conteúdo até o projeto gráfico do mesmo. Quanto às variáveis sob a forma de dummy, ambas medem o nível de disclosure das empresas de maneira indireta: a primeira variável estava relacionada ao fato de a empresa ser ou não emissora de ADR e a outra estava relacionada ao fato de a empresa estar ou não em algum dos níveis diferenciados de Governança. Apesar da maior exigência que recai sobre as empresas emissoras de ADR e/ou pertencentes ao Novo Mercado, isto não necessariamente implica que outras empresas não possam, também, apresentar uma alta qualidade no seu nível de divulgação de informações. Para o cálculo do custo de capital próprio, a autora utiliza 3 diferentes alternativas, mas não deixa claro que faz uso apenas de ações ordinárias ou se há ações ordinárias e preferenciais sendo usadas indistintamente. Os resultados das estimações foram ora negativos e significantes, conforme esperado pela teoria, ora não significantes, dependendo da forma como o modelo era especificado.

Mazer (2007) também relaciona custo de capital ao nível de disclosure, porém utiliza basicamente ações preferenciais, sob a justificativa de que estas são as ações mais líquidas no mercado brasileiro. Como índice de disclosure, a autora usou um questionário baseado em pesquisas anteriores. Seus resultados indicaram que não é possível afirmar que existe relação entre as duas variáveis estudadas.

Nota-se, portanto, que as pesquisas brasileiras sobre este tema têm uma maior inclinação a não comprovar a existência de uma relação entre custo de capital próprio e o nível de disclosure das empresas. Certamente há pequenas diferenças na forma como as pesquisas são desenvolvidas, mas mesmo isto não faz com que resultados diferentes sejam consistentemente obtidos. A partir deste panorama, será apresentada a seguir a metodologia empregada nesta pesquisa, destancando-se especialmente os pontos em que ela difere das pesquisas anteriores sobre o assunto. 
A relação entre o nível voluntário de transparência e o custo de capital próprio das empresas brasileiras não-financeiras

\section{METODOLOGIA}

Dentre os pesquisadores deste tema, vários deles construíram algum tipo de medida do nível de disclosure de empresas. Botosan (1997) construiu um índice de disclosure com 35 itens separados em 5 categorias distintas, tomando por base o relatório anual publicado pelas empresas. Botosan e Plumlee (2001), medem o nível de disclosure utilizando o Report of the Financial Analysts Federation's Corporate Information Committee, publicado pela Association for Investment and Management Research (AIMR). Outros índices também foram elaborados por Hail (2002), Eng e Mak (2003) e Lanzana (2004).

A fim de calcular um índice de disclosure para esta pesquisa, foi utilizado o questionário desenvolvido por Lanzana (2004). A razão desta escolha se dá porque o mesmo busca quantificar e qualificar, a partir do relatório anual (RA) publicado voluntariamente pelas empresas, diferentes tipos de informação, financeiras ou não. Na maioria das vezes, os documentos foram obtidos nos próprios sítios de Internet das empresas. O questionário era composto por 33 itens, divididos em 4 dimensões: (1) Informações gerais e não financeiras; (2) Informações financeiras; (3) Análise de tendências e análise gerencial e (4) Risco, criação de valor e projeções.

Para cada um dos itens foi atribuído o valor 0 (zero), 1 (um) ou 2 (dois), que indicam se a informação está presente (1 ou 2) ou não (0) no RA. Em alguns critérios, foi atribuído 1 se a informação estivesse disponível e 2 se, além da informação estabelecida pelo critério, o relatório contivesse valores quantitativos ou o detalhamento da mesma.

A estrutura do índice de disclosure proposto por Lanzana (2004) utilizado nesta pesquisa, assim como os critérios para pontuação de cada um de seus 33 itens, são apresentados a seguir:

(a) Informações Gerais e Não-financeiras

Q1) Descrição do negócio e principais produtos: a empresa computa 2 pontos se o RA apresentar descrição geral sobre as atividades da companhia, os produtos e segmentos em que atua;

Q2) Principais mercados e market share: se o RA listar os principais mercados compradores dos produtos da empresa, é computado 1 ponto; se o relatório apresentar o valor da participação de mercado da empresa ou percentual da receita derivado de cada mercado, a empresa computa 2 pontos;

Q3) Estratégia (metas e objetivos): caso o relatório apresente uma descrição geral da estratégia da empresa, é computado 1 ponto; caso exista descrição em termos quantitativos da 
estratégia ou metas e objetivos, são computados 2 pontos;

Q4) Ambiente de negócio e fatores críticos de sucesso: se o RA apresentar uma descrição do ambiente de negócios em termos macroeconômicos e/ou do segmento em que atua e dos fatores críticos de sucesso para a empresa ter obtido determinado resultado em relação aos competidores, a empresa recebe 2 pontos;

Q5) Eventos importantes no ano: se o relatório apresentar a descrição dos principais eventos corporativos ocorridos ao longo do ano, são computados 2 pontos;

Q6) Estrutura organizacional: a empresa recebe 2 pontos se o relatório contiver o nome e o cargo dos principais gestores da companhia;

Q7) Governança corporativa: a empresa computa 1 ponto se houver uma descrição geral da estrutura de Governança da empresa no RA; se for uma descrição detalhada da estrutura de Governança (nível de contato com investidores externos, estrutura do conselho de administração, presença de comitê de auditoria, comitê de compensação), a empresa computa 2 pontos;

Q8) Relatório social: se o relatório traz as ações realizadas em relação à responsabilidade social, investimento nos empregados e proteção ambiental, a empresa computa 1 ponto; se houver um valor monetário para estes investimentos, a empresas computa 2 pontos;

Q9) Investimentos em recursos humanos e desenvolvimento gerencial: caso o relatório contenha descrição genérica das ações voltadas ao desenvolvimento dos empregados da empresa, ela computa 1 ponto; se houver valor quantitativo do investimento nessas ações, a empresa computa 2 pontos;

Q10) Investimentos em pesquisa e desenvolvimento e outros ativos intangíveis: deve haver um relato geral das ações voltadas a pesquisa e desenvolvimento e/ou atualização tecnológica, investimento na construção da marca e outros ativos intangíveis, para a empresa ganhar um 1 ponto; se neste relato houver quantificação do investimento, a empresa ganha 2 pontos;

Q11) Eficiência operacional: uma descrição geral das medidas de eficiência operacional deverá constar no RA da empresa para que ela compute 1 ponto neste critério; se ela apresentar medidas quantitativas da eficiência operacional, ela computa 2 pontos.

(b) Informações Financeiras

Q12) Unidades vendidas: a quantidade das vendas nos 2 últimos anos quando presente 
A relação entre o nível voluntário de transparência e o custo de capital próprio das empresas brasileiras não-financeiras

no RA, faz com que a empresa compute 1 ponto; ela pode computar 2 pontos se a quantidade das unidades vendidas for mencionada para mais de 2 anos;

Q13) ROE (Retorno sobre patrimônio líquido): a empresa computa 1 ponto se o RA apresentar os valores para os 2 últimos anos e 2 pontos se as informações apresentadas forem superiores a 2 anos;

Q14) ROA (Retorno sobre ativo): a empresa computa 1 ponto se o RA apresentar os valores para os 2 últimos anos e 2 pontos se as informações apresentadas forem superiores a 2 anos;

Q15) EBITDA: a empresa computa 1 ponto se o RA apresentar os valores para os 2 últimos anos e 2 pontos se as informações apresentadas forem superiores a 2 anos;

Q16) Demonstração de fluxo de caixa: a empresa computa 1 ponto se o RA apresentar os valores para os 2 últimos anos e 2 pontos se as informações apresentadas forem superiores a 2 anos.

(c) Análise de Tendências e Análise Gerencial

Q17) Tendência de receita ao longo dos últimos anos: caso o RA contenha uma descrição geral da tendência da receita operacional ao longo dos últimos anos, a empresa recebe 1 ponto; caso ele apresente dados quantitativos para explicar a tendência da receita nos últimos anos, ela recebe 2 pontos;

Q18) Vendas por região e/ou unidade de negócio: se constar o valor da receita por unidade de negócio ou região, a empresa computa 2 pontos;

Q19) Tendência do lucro operacional ao longo dos últimos anos: para a empresa computar 1 ponto neste critério, o RA deverá conter a descrição geral da tendência do lucro operacional ao longo dos últimos anos; se essa tendência for apresentada em dados quantitativos, a empresa computa 2 pontos;

Q20) Lucro operacional por região e/ou unidade de negócio: se no RA constar o valor do lucro operacional por unidade de negócio ou região, a empresa recebe 2 pontos;

Q21) Tendência dos investimentos ao longo dos últimos anos: o RA deve conter uma descrição geral da tendência dos investimentos ao longo dos últimos anos para que a empresa compute 1 ponto, e os dados quantitativos desses investimentos para que a empresa compute 2 pontos;

Q22) Investimento por região e/ou unidade de negócio: se constar o valor do investimento por unidade de negócio no RA, a empresa recebe 1 ponto;

Q23) Tendência de comportamento das ações e retorno total para o acionista: se o 
relatório mostrar o retorno obtido ou o comportamento da ação ao longo do ano e dividendo proposto a ser distribuído, a empresa recebe 2 pontos;

Q24) Discussão sobre mudanças na receita e market share: a empresa pode obter 1 ponto se apresentar uma discussão geral das mudanças de um ano para outro e 2 pontos se o RA apresentar valores para as mudanças;

Q25) Discussão sobre mudanças no lucro operacional: a empresa pode obter 1 ponto se apresentar uma discussão geral das mudanças de um ano para outro e 2 pontos se o RA apresentar valores para as mudanças;

Q26) Discussão sobre mudanças nos investimentos ou pesquisa e desenvolvimento: a empresa pode obter 1 ponto se apresentar uma discussão geral das mudanças de um ano para outro e 2 pontos se o RA apresentar valores para as mudanças.

(d) Risco, Criação de Valor e Projeções

Q27) Gestão de risco: caso o RA contenha uma descrição geral das ações adotadas na área de gestão de risco a empresa computa 1 ponto, e se ela divulgar o valor do investimento em gestão de risco, ela computa 2 pontos;

Q28) Exposição ao risco cambial: a empresa computa 1 ponto se o RA trouxer uma descrição geral das medidas de proteção ao risco cambial e 2 pontos se divulgar dados quantitativos sobre a exposição deste risco;

Q29) Medidas quantitativas de criação de valor para o acionista: a divulgação de medidas quantitativas de criação de valor para o acionista faz com que a empresa compute 2 pontos, e caso ela apenas divulgue informações qualitativas sobre este critério, ela computa 1 ponto;

Q30) Compensação gerencial: se o RA da empresa fizer apenas uma descrição geral das políticas de compensação gerencial, ela recebe 1 ponto; se o valor numérico dessas recompensas estiver presente, ela recebe 2 pontos;

Q31) Perspectivas de novos projetos: caso as perspectivas para novos projetos em desenvolvimento ou a serem desenvolvidos estiverem presentes no relatório, a empresa computa 1 ponto; se as informações sobre estas perspectivas forem quantitativas, ela computa 2 pontos;

Q32) Projeções de lucro: se o relatório mencionar apenas uma descrição geral das perspectivas de lucro para o próximo ano, a empresa computa 1 ponto; se esta projeção contiver informações quantitativas para o próximo ano, ela computa 2 pontos; 
A relação entre o nível voluntário de transparência e o custo de capital próprio das empresas brasileiras não-financeiras

Q33) Projeções de venda e crescimento: se o relatório mencionar apenas uma descrição geral das perspectivas de vendas e crescimento para o próximo ano, a empresa computa 1 ponto; se esta projeção contiver informações quantitativas para o próximo ano, ela computa 2 pontos.

Além da necessidade de medir o nível de disclosure voluntário das empresas, é preciso também medir seus custos de capital próprio. Mais amplamente, o custo de capital é a taxa de retorno que a empresa precisa obter sobre seus projetos de investimentos a fim de manter o valor de mercado de suas ações e atrair recursos para si. O custo de capital próprio não é uma variável diretamente observável, porém, com o CAPM de Sharpe (1964) e Lintner (1965) é possível obter uma estimativa deste valor. Conforme Botosan (1997), a utilização do beta como proxy é mais adequada que o uso, por exemplo, de retornos realizados, uma vez que esta última poderia estar contaminada por outros ruídos do mercado.

Conforme o CAPM, a taxa de retorno requerida por um investidor é igual ao retorno dos investimentos sem risco acrescido de um prêmio pelo risco. $\mathrm{O}$ risco de um ativo pode ser decomposto em risco sistêmico (não-diversificável) e específico (diversificável). Segundo a teoria, o mercado deveria compensar os investidores por incorrerem no risco sistêmico, mas não por incorrerem no risco específico, que pode ser diversificado combinando-se ativos em uma carteira. Assim, o CAPM pode ser descrito pela seguinte equação:

$$
R_{i}=R_{f}+\beta_{i}\left(R_{m}-R_{f}\right),
$$

tal que $R_{i}$ é a taxa de retorno esperada do ativo $i, R_{f}$ é a taxa de retorno esperada do ativo livre de risco, $R_{m}$ é a taxa de retorno esperada da carteira de mercado e $\beta_{i}$ é a medida do risco sistêmico do ativo $i$.

Como a taxa de retorno esperada para o ativo é diretamente proporcional à medida de risco e todas as outras variáveis têm valor igual para todas empresas em um mesmo instante de tempo, é possível, para efeito desta pesquisa, utilizar o beta do ativo como uma proxy para o custo de capital próprio da empresa. A carteira de mercado utilizada na pesquisa foi o Índice BOVESPA, IBOVESPA.

A fim de verificar a existência ou não de relação entre o nível de disclosure e o custo de capital próprio de empresas brasileiras não financeiras, o seguinte modelo foi proposto:

$$
\beta_{i, t}=\alpha_{0}+\gamma_{1} I D L_{i, t-1}+\sum_{j=1}^{n} \delta_{j} V C_{i, t-1}+\varepsilon_{i, t}
$$

tal que, $\beta_{i, t}$ é a proxy para o custo de capital próprio da i-ésima empresa no tempo $t, V C_{i, t-1}$ é 
o conjunto de variáveis de controle da empresa $i$ no tempo $t-1, I D L_{i, t-1}$ representa o índice de disclosure da i-ésima empresa no tempo $t-1$ e $\varepsilon_{i, t}$ é o termo de erro da equação. Os coeficientes $\alpha_{0}, \gamma_{1}$ e $\delta_{j}$ são, respectivamente, o intercepto da equação, o coeficiente associado ao índice de disclosure e o conjunto de $n$ coeficientes associados às variáveis de controle.

O $\beta$ de cada empresa para cada ano foi calculado utilizando-se as taxas de retorno semanais do IBOVESPA e da ação ordinária das empresas da amostra. Foram utilizadas exclusivamente as ações ordinárias por serem estes acionistas os que detêm o controle de suas respectivas empresas e que podem, com maior poder, exigir o disclosure de informações por parte dos gestores das companhias.

As variáveis de controle são empregadas nesta pesquisa para garantir uma maior qualidade das análises. Seu uso busca eliminar dos resultados encontrados possíveis relações espúrias observadas entre as variáveis de interesse: o custo de capital próprio e o nível de disclosure das empresas. Foram utilizadas as seguintes variáveis de controle: grau de endividamento, tamanho da empresa, liquidez em bolsa e índice market-to-book.

O grau de endividamento foi medido da seguinte maneira: endividamento total dividido pelo ativo total, tal que endividamento total é dado pela soma dos financiamentos de curto (FCP) e longo prazo (FLP), debêntures de curto (DCP) e longo prazos (DLP). Segundo a teoria, é esperado que as empresas mais endividadas sejam mais monitoradas por seus credores, e, consequentemente, apresentem um maior nível de disclosure voluntário.

Para Barros (2001), empresas maiores podem apresentar um nível de endividamento relativo superior a empresas de menor porte por possuírem condições privilegiadas de crédito. Assim, uma variável capaz de capturar o tamanho das empresas foi empregada nesta pesquisa. O tamanho foi calculado como o logaritmo natural da receita operacional líquida. Alternativamente, o logaritmo natural do ativo total foi utilizado como outra proxy para o tamanho da empresa.

A variável Market-to-Book é calculada pela seguinte equação:

$$
M t B=\left(\frac{P A}{V P A}\right),
$$

tal que $P A$ representa o preço unitário da ação e $V P A$ representa o valor patrimonial da ação. Os valores para o preço das ações correspondem ao preço de fechamento da ação no último dia do ano. Caso não houvesse negociação da ação neste dia, foi permitida uma tolerância de 
A relação entre o nível voluntário de transparência e o custo de capital próprio das empresas brasileiras não-financeiras

até 40 dias para a verificação do preço. Caso não houvesse negociação da ação também dentro do prazo de tolerância, a empresa era excluída da amostra no referido ano. Os valores do patrimônio líquido por ação estão limitados ao balanço dos últimos 6 meses do ano de referência.

O índice $M t B$ representa a distância entre o valor contábil e as expectativas de mercado. Um valor de $M t B$ mais alto pode indicar maiores oportunidades de crescimento, menores riscos percebidos pelo mercado ou um maior conservadorismo contábil.

A liquidez em bolsa das ações no mercado, conforme Lanzana (2004), é um importante fator na análise do disclosure. A autora assume que empresas com maior liquidez em bolsa possuem seu capital distribuído entre um maior número de acionistas e, por isso, devem apresentar um maior índice de disclosure.

A fim de não comprometer os resultados desta pesquisa por conta da utilização de empresas que apresentam baixo índice de negociação em bolsa, as empresas que fazem parte da amostra deveriam apresentar liquidez em bolsa maior que 0,01, sendo liquidez em bolsa calculada pela seguinte equação:

$$
L A=100 \times \frac{p}{P} \times \sqrt{\left(\frac{n}{N}\right) x\left(\frac{v}{V}\right)},
$$

tal que, $p$ representa o número de dias em que houve pelo menos uma negociação com a ação dentro do período escolhido, $P$ o número total de dias do período, $n$ o número de negócios com todas as ações dentro do período escolhido, $v$ o volume em dinheiro das negociações com as ações dentro do período escolhido e $V$ o volume em dinheiro de todas as negociações com ações dentro do período escolhido. Este critério de corte para seleção amostral se faz necessário para que empresas com baixo índice de liquidez em bolsa sejam excluídas da amostra. Tais empresas são as mais prováveis a terem uma série de preços com muitos dados faltantes, causando problemas especialmente no cálculo da variável beta.

Além dos controles descritos anteriormente, o nível de Governança Corporativa das empresas, conforme a classificação BOVESPA, foi utilizado como variável dummy no modelo de regressão. Quanto ao tamanho da amostra, este foi determinado pelo número de empresas não financeiras que pertenciam a algum nível de Governança Corporativa até o final de 2006 e que publicaram relatório anual em pelo menos um dos anos de 2004 até 2006, e que tivessem índice de liquidez em bolsa superior a 0,01. Os betas das empresas foram calculados, portanto, para o período de 2005 a 2007. Foram escolhidas apenas empresas classificadas dentro de algum dos níveis de Governança Corporativa da BOVESPA, pois estas seriam, em 
princípio, as empresas com maior chance de, voluntariamente, divulgar informações em seus relatórios anuais.

Foi avaliada a relação entre o nível de disclosure da empresa e o custo do capital próprio no ano seguinte ao da publicação do relatório anual da empresa. Desta forma, uma eventual relação entre o nível de disclosure obtido com as informações publicadas no relatório anual do ano $t$ e o custo de capital próprio medido no ano $t+1$ foi investigada. A amostra final contou com 46 empresas. Nos 3 anos investigados, isto proporcionou um total de 91 relatórios anuais, pois algumas empresas não atendiam aos critérios de seleção amostral em todos os três anos pesquisados. A quantidade de observações por exercício está apresentada na Tabela 1. A Tabela 2 classifica as empresas de acordo com seus respectivos níveis de Governança na BOVESPA.

\begin{tabular}{|c|c|}
\hline Exercício & Observações \\
\hline 2004 & 19 \\
\hline 2005 & 26 \\
\hline 2006 & 46 \\
\hline Total & 91 \\
\hline
\end{tabular}

Tabela 2 - Quantidade de Observações por Nível de Governança Corporativa

\begin{tabular}{lr}
\hline NGC & Observações \\
\hline Nenhum & 2 \\
Nível 1 & 42 \\
Nível 2 & 4 \\
Novo Mercado & 43 \\
Total & 91 \\
\hline \multicolumn{2}{c}{ Fonte: os autores }
\end{tabular}

\section{RESULTADOS}

A Tabela 3 apresenta um resumo das estatísticas descritivas das variáveis. O beta médio das 91 observações foi de 0,608, com mediana de 0,610. O índice de disclosure médio foi de 44,7 pontos, com mediana de 46. A partir desses valores e dos valores do primeiro e terceiro quartis é possível perceber que essas duas variáveis são razoavelmente simétricas, uma característica importante na estimação do modelo de regressão.

Tabela 3 - Estatística descritiva das variáveis

\begin{tabular}{lrrrrr}
\hline \multicolumn{1}{c}{ Variável } & Média & \multicolumn{1}{c}{ Desvio } & \multicolumn{1}{c}{ 1o qt. } & Mediana & \multicolumn{1}{c}{ 3o qt. } \\
\hline Beta & 0,608 & 0,476 & 0,400 & 0,610 & 0,942 \\
Liquidez & 0,208 & 0,372 & 0,005 & 0,031 & 0,282
\end{tabular}


A relação entre o nível voluntário de transparência e o custo de capital próprio das empresas brasileiras não-financeiras

\begin{tabular}{lrrrrr} 
MtB & 5,285 & 14,632 & 1,720 & 2,640 & 4,040 \\
Log AT & 15,107 & 1,759 & 13,872 & 15,253 & 16,516 \\
Log RL & 14,598 & 1,506 & 13,909 & 14,559 & 15,862 \\
Alavancagem & 0,262 & 0,160 & 0,137 & 0,286 & 0,380 \\
IDL & 44,734 & 10,339 & 40 & 46 & 52 \\
\hline \multicolumn{5}{c}{ Fonte: os autores }
\end{tabular}

O modelo proposto foi estimado pelo método dos mínimos quadrados ordinários com erros robustos a heterocedasticidade e autocorrelação por meio da correção de White. Não há indícios de problemas de multicolinearidade entre as variáveis, pois os fatores de inflação da variância são todos menores que 10. De acordo com os resultados do teste RESET de Ramsey, não há problemas de má especificação do modelo estimado. Os resultados estão apresentados na Tabela 4.

Tabela 4 - Resultados da estimação do primeiro modelo

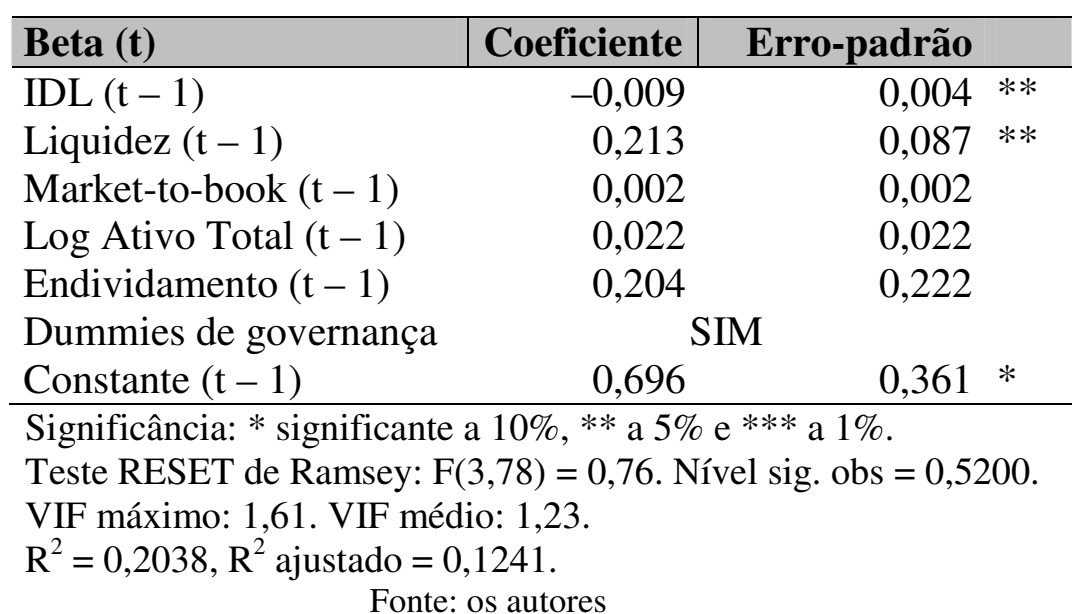

A partir dos resultados deste primeiro modelo é possível afirmar que há relação negativa e significante entre o índice de disclosure voluntário e o custo de capital próprio das empresas no nível de 5\%. Os resultados revelaram ainda que a variável liquidez tem relação significante e positiva com o beta no nível de 5\%. Todas as demais variáveis não se mostraram significativamente relacionadas com a variável dependente.

Alternativamente, com forma de avaliar a robustez dos resultados encontrados, o modelo foi estimado substituindo-se o logaritmo natural do ativo total pelo logaritmo natural da receita líquida como proxy para o tamanho da empresa. Os resultados estão apresentados na Tabela 5. Da mesma forma que o modelo anterior, a hipótese nula de que não há relação entre o nível de disclosure e o custo de capital próprio das empresas foi rejeitada no nível de $5 \%$ de significância. O coeficiente negativo associado à variável IDL implica que empresas que apresentam um maior nível de evidenciação voluntária de informações apresentam um 
menor custo de capital próprio. As relações significantes e positivas do beta com a variável liquidez foi mantida. Também não foram verificados problemas de multicolinearidade nem de má especificação do modelo. Os valores dos fatores de inflação da variância (máximo e médio) assim como o resultado do teste RESET de Ramsey estão apresentados no rodapé da Tabela 5.

Tabela 5 - Resultados da estimação do modelo alternativo

\begin{tabular}{lrr}
\hline Beta (t) & Coeficiente & Erro-padrão \\
\hline IDL $(\mathrm{t}-1)$ & $-0,009$ & $0,004 * *$ \\
Liquidez $(\mathrm{t}-1)$ & 0,230 & $0,089 * *$ \\
Market-to-book $(\mathrm{t}-1)$ & 0,001 & 0,002 \\
Log Receita Líquida $(\mathrm{t}-1)$ & 0,013 & 0,027 \\
Endividamento $(\mathrm{t}-1)$ & 0,225 & 0,227 \\
Dummies de governança & \multicolumn{2}{c}{ SIM } \\
Constante ( -1$)$ & 0,854 \\
\hline Significância: * significante a 10\%, ** a 5\% e *** a 1\%. \\
Teste RESET de Ramsey: F(3,77)=0,68. Nível sig. obs $=0,5672$. \\
VIF máximo: 1,74. VIF médio: $1,26$. \\
$\mathrm{R}^{2}=0,1953, \mathrm{R}^{2}$ ajustado $=0,1148$. \\
\multicolumn{2}{c}{ Fonte: os autores }
\end{tabular}

Este resultado corrobora os achados anteriores de Botosan (1997), Botosan e Plumlee (2001) e Hail (2002), além do resultado encontrado por Gomes (2006) com dados de empresas brasileiras. A distinta abordagem metodológica empregada nesta pesquisa ao utilizar uma forma diferente de calcular o índice de disclosure, ou a própria composição amostral, talvez tenha sido a razão para que os resultados apresentados tenham sido diferentes daqueles encontrados por Alencar (2005) e Mazer (2007), também com dados de empresas brasileiras.

Todavia, os resultados apresentados são passíveis das seguintes críticas: a medida empregada para calcular o nível de disclosure pode ainda não ser a mais adequada, ou, também, pode não conter todos os elementos informacionalmente importantes para a análise por parte dos investidores e demais interessados nas empresas; o cálculo do custo de capital próprio poderia ter sido estimado de maneira diferente, utilizando-se outro modelo; as variáveis de controle para os constructos teóricos utilizados poderiam ser outras ou novas variáveis de controle poderiam ser adicionadas. Ademais, calcular o custo de capital próprio baseando-se em ações preferenciais tem também algum apelo para estudos futuros. Isto porque, sendo estes os acionistas mais desprotegidos, o disclosure pode ter sobre eles um efeito diferente do que tem para os acionistas ordinários. 
A relação entre o nível voluntário de transparência e o custo de capital próprio das empresas brasileiras não-financeiras

\section{CONCLUSÃO}

Esta pesquisa teve como objetivo principal verificar se há relação significante entre o custo de capital próprio em empresas brasileiras não financeiras e seu nível de disclosure, e se esta relação é negativa conforme esperado pela teoria. A pesquisa apoiou-se em estudos anteriores para definir um conjunto de variáveis de controle que potencialmente poderiam interferir com os resultados. Além disso, foi utilizado um questionário desenvolvido por Lanzana (2004) para o cálculo do índice de disclosure das empresas.

Foi encontrada uma relação negativa e significante entre as variáveis de interesse, fato que tem significado intuitivo, pois o fornecimento voluntário de informações por parte da empresa é visto como uma coisa boa por parte do mercado de capitais. O maior disclosure causa no acionista uma percepção de risco mais baixo, e, portanto, a empresa tem como recompensa um menor custo de capital próprio.

Este resultado corrobora parte dos resultados encontrados por Gomes (2006) com dados de empresas brasileiras e refuta os encontrados por Alencar (2005) e Mazer (2007), também para o mercado brasileiro. Internacionalmente, resultados semelhantes foram encontrados por Botosan (1997), Botosan e Plumlee (2001) e Hail (2002). Cabe ressaltar que foram estimados dois modelos, fazendo variar entre eles unicamente a forma como a variável tamanho era mensurada. A relação entre o nível de disclosure e o custo de capital próprio se mostrou negativa e significante tanto quando o logaritmo natural do ativo total como o logaritmo natural da receita líquida foi empregada como proxy para a tamanho das empresas, indicando certa robustez.

Encontrar uma relação significante em um estudo que relaciona disclosure e custo de capital tem um apelo importante, haja vista que a maioria das pesquisas anteriores não conseguiu verificar tal relação. Para o desenvolvimento do mercado de capitais brasileiro, este resultado é especialmente importante, pois pode influenciar outras empresas a tomarem a decisão de evidenciar mais e melhor, quantitativamente e qualitativamente, diminuindo a assimetria de informações existente entre os gestores e os investidores.

\section{REFERÊNCIAS}

ALENCAR, Roberta C. Custo do capital próprio e nível de disclosure nas empresas 
Francisco Henrique Figueiredo de Castro Junior, Paula Meneghesso da Conceição \& Débora Antunes Santos

brasileiras. Brazilian Business Review. Vitória, vol. 2, no. 1, p. 1-12, 2005.

AMIHUD, Yakov; MENDELSON, Haim. Liquidity, assets prices and financial policy. Financial Analysts Journal. Vol. 47, no. 6, p. 56-66, 1991.

BARROS, Lucas A. B. C. Estrutura de capital e valor da empresa no contexto de assimetria de informações e relações de agência: um estudo empírico. Dissertação (Mestrado em Administração). Faculdade de Economia, Administração e contabilidade da Universidade de São Paulo. São Paulo, 2001.

BARRY, C. B.; BROWN, S. J. Differential information and security market equilibrium. Journal of Financial and Quantitative Analysis. Vol. 20, no. 4, p. 407-422, 1985.

BLOOMFIELD, Robert J., WILKS, T. Jeffrey. Disclosure effects in the laboratory: liquidity, depth, and the cost of capital. The Accounting Review. Vol. 75, no.1, 2000.

BOTOSAN, Christine A. Disclosure level and the cost of equity capital. The Accounting Review. Vol. 72, no. 3, p. 323-349, 1997.

BOTOSAN, Christine A.; PLUMLEE Marlene A. Estimating expected cost of capital: a theory-based approach. SSRN Working paper. Disponível em: http://papers.ssrn.com/sol3/papers.cfm?abstract_id=279309. Acesso em: 15/11/ 2007, 2001.

BROWN, S.; FINN, M.; HILLEGEIST,S. A. Disclosure quality and the probability of informed trade. Working Paper. Kellogg School of Management, Northwestern University, 2001.

BUSHMAN, Robert M.; SMITH, Abbie J. Transparency, financial accounting information, and corporate governance. Economic Policy Review. Vol. 9, no. 1, p. 65-87, 2003.

BUSHMAN, Robert; PIOTROSKI, J.; SMITH, Abbie J. What determines corporate transparency? Journal of Accounting Research. Vol. 42, no. 2, p. 207-252, 2004.

COLES, J. L.; LOEWENSTEIN, U.; SUAY, J. On equilibrium pricing under parameter 
A relação entre o nível voluntário de transparência e o custo de capital próprio das empresas brasileiras não-financeiras

uncertainty. Journal of Financial and Quantitative Analysis. Vol. 30, p.347-364, 1995.

CVM. Recomendações da CVM sobre governança corporativa. Disponível em: www.cvm.gov.br/port/public/publ/cartilha/cartilha.doc. Acesso em 05/11/2007, 2002.

DIAMOND, D.; VERRECCHIA, R. Disclosure, liquidity, and the cost of equity capital. The Journal of Finance, Vol. 46, no. 4, p. 1327-1359, 1991.

ENG, L. L.; MAK, Y. T. Corporate governance and voluntary disclosure. Journal of Accounting and Public Policy. Vol. 22, p. 325-345, 2003.

GARCIA, Fábio G.; SATO, Lívia G.; CASELANI, César N. O impacto da política de transparência sobre o valor das empresas brasileiras. In: 4o Encontro Brasileiro de Finanças, Rio de Janeiro, 2004.

GLOSTEN, Laurence; MILGROM, Paul R. Bid ask and the transation prices in a specialist market with heterogeneously informed traders. Journal of Financial Economics. Vol. 14, no. 1, p. 71-100, 1985.

GOMES, Elizabeth A. Estudo sobre os níveis de disclosure adotados pelas empresas brasileiras e custo de capital. Dissertação (Mestrado em Administração de Empresas). Universidade Presbiteriana Mackenzie. São Paulo, 2006.

HAIL, L. The Impact of voluntary corporate disclosures on the ex ante cost of capital for Swiss firms. European Accounting Review. Vol. 11, no. 4, p. 741-773, 2002.

HANDA, P.; LINN S. Arbitrage pricing with estimation risk. Journal of Financial Economics. Vol. 28, p. 81-100, 1993.

HEALY, Paul M.; PALEPU, Krishna G. Information asymmetry, corporate disclosure, and the capital markets: a review of the empirical disclosure literature. Journal of Accounting an Economics. Vol. 31, no. 1-3, p. 405-440, 2000.

IBGC. Código das melhores práticas de Governança Corporativa, 4a ed. São Paulo: IBGC, 2009. 
Francisco Henrique Figueiredo de Castro Junior, Paula Meneghesso da Conceição \& Débora Antunes Santos

KLEIN, R.; BAWA, V. The effect of estimation risk on optimal portfolio choice. Journal of Financial Economics. Vol. 3, no. 3, p. 215-231, 1976.

LANZANA, Ana P. Relação entre disclosure e governança corporativa das empresas brasileiras. Dissertação (Mestrado em Administração). Faculdade de Economia, Administração e Contabilidade da Universidade de São Paulo. São Paulo, 2004.

LIMA, Gerlando et al. Influência do disclosure voluntário no custo de capital de terceiros. In: 7o Congresso USP de Controladoria e Contabilidade. São Paulo, 2007.

LINTNER, J. The valuation of risk assets and the selection of risk investments in stock portfolios and capital budgets. Review of Economic and Statistics. Vol. 47, p. 13-37, 1965.

MALACRIDA, Mara J. C.; YAMAMOTO, Marina M. Governança corporative: nível de evidenciação das informações e sua relação com a volatidade das ações do IBOVESPA. Revista de Contabilidade e Finanças. São Paulo, Vol. 3, p. 65-79, 2006.

MAZER, Lílian P. O impacto do nível de transparência no custo do capital próprio das empresas do Ibovespa. Dissertação (Mestrado em Administração). Faculdade de Economia, Administração e Contabilidade de Ribeirão Preto da Universidade de São Paulo. São Paulo, 2007.

SHARPE, William F. Capital asset prices: a theory of market equilibrium under conditions of risk. Journal of Finance. Vol. 19, no. 3, p. 425-442, 1964.

VERRECCHIA, Robert E. Essays on disclosure. Journal of Accounting and Economics. Vol. 32, no. 1-3, p. 97-480, 2001. 